vaccine each winter for four years was very little lower than that in children who had had influenza B vaccines. ${ }^{17}$ More information on this phenomenon is needed, but it does argue a conservative approach to recommendations for annual vaccination of the general population against the later $\mathrm{H} 3 \mathrm{~N} 2$ variants.

1 World Health Organisation. Recommended composition of influenza vaccines for use in the 1980-81 season. Weekly Epidemiological Record $1980 ; 55: 73$.

2 Anonymous. A "new" influenza virus? Br Med 7 1978;ii:230.

3 Oxford JS, McGeoch DJ, Schild GC, Beare AS. Analysis of virion RNA segments and polypeptides of influenza $A$ virus recombinants of defined virulence. Nature 1978;273:778-9.

4 DHSS. Influenza. CMO (79)11.

5 Anonymous. Influenza 1978-9. Br Med 7 1978;ii:1177.

6 Tillett HE, Smith JWG, Clifford RE. Excess morbidity and mortality associated with influenza in England and Wales. Lancet 1980;i:793-5.

? Schonberger LB, Bregman DJ, Sullivan-Bolyai JZ, et al. Guillain-Barré syndrome following vaccination in the national influenza immunization program, United States, 1976-77. Am F Epidemiol 1979;110:105-23.

8 Tyrrell DAJ, Smith JWG. Vaccination against influenza A. Br Med Bull $1979 ; 35: 77-85$.

9 Smith JWG, Pollard R. Vaccination against influenza: a five-year study in the Post Office. F Hyg (Camb) $1979 ; 83: 157-70$.

${ }^{10}$ Francis T, Davenport FM, Hennessey AV. A serological recapitulation of human infection with different strains of influenza virus. Trans Assoc Am Physicians 1953;66:231-9.

11 Laver WG, Downie JC, Webster RG. Studies on antigenic variation in influenza virus. Evidence for multiple antigenic determinants on the hemagglutinin subunits of A-Hong Kong-68 (H3N2) virus and the A-England-72 strains. Virology $1974 ; 59: 230-44$.

12 Webster RG, Kasel JA, Couch RB, Laver WG. Influenza virus subunit vaccines. II. Immunogenicity and original antigenic sin in humans. f Infect Dis 1976;134:48-58.

$13 \mathrm{Smith}$ AJ, Davies JR. The response to inactivated influenza A (H3N2) vaccines: the development and effect of antibodies to the surface antigens. $\mathcal{f} \mathrm{Hyg}$ (Camb) $1977 ; 78: 363-5$.

14 Schild GC, Smith JWG, Cretescu L, Newman RW, Wood JM. Strainspecificity of antibody to haemagglutinin following inactivated A/Port Chalmers/1/73 vaccine in man: evidence for a paradoxical strain-specific antibody response. Dev Biol Stand 1977 ;39:273-81.

15 Oxford JS, Schild GC, Potter CW, Jennings R. The specificity of the antihaemagglutinin antibody response induced in man by inactivated influenza vaccines and by natural infection. f Hyg (Camb) 1979;82: 51-61.

${ }^{16}$ Virelizier J-L. Host defenses against influenza virus: the role of antihemagglutinin antibody. $\mathcal{F}$ Immunol 1975 ;115:434-9.

17 Hoskins TW, Davies JR, Smith AJ, Miller CL, Allchin A. Assessment of inactivated influenza- $A$ vaccine after three outbreaks of influenza $A$ at Christ's Hospital. Lancet 1979 ; : $: 33-5$.

\section{Refractory anaemia}

The term refractory anaemia was used by Bomford and Rhoads $^{1}$ to describe a group of patients with anaemia of unknown aetiology and characterised by "failure to respond favourably to the exhibition of substances which cure the great majority of cases of anaemia." With improved diagnostic techniques and better understanding some of the patients included in this early study would now be identified as having aplastic anaemia, myelosclerosis, sideroblastic anaemia, or congenital dyserythropoietic anaemia. ${ }^{2}$ These cases apart, there remains a syndrome of primary refractory anaemia characterised by a qualitative disturbance of erythropoiesis with morphologically and functionally abnormal erythroid cells and also with a variable degree of disturbed myelopoiesis. ${ }^{2}$ Two types of chronic refractory cytopenia have been recognised in which general haemopoietic defects are particularly prominent. Sometimes known collectively as the myelodysplastic syndromes these are refractory anaemia with excess of myeloblasts, ${ }^{34}$ and refractory anaemia with proliferative dysplasia. ${ }^{5}$

Refractory anaemia with excess of myeloblasts is found in elderly patients who present with-symptoms due to pancyto- penia. The bone marrow is of normal or increased cellularity with $30-35 \%$ myeloblasts and promyelocytes, and one view is that the disorder may be a form of leukaemia or smouldering leukaemia. ${ }^{6} 7$ Though a few cases undoubtedly terminate in acute leukaemia, however, many others remain stable with an unchanging bone marrow for years. Culture studies in the $\stackrel{.}{.}$ laboratory can be used to distinguish those cases of refractory $\vec{\Rightarrow}$ anaemia with excess of myeloblasts that are essentially benign $\stackrel{?}{?}$ from those which are preleukaemic; in the benign form the capacity for forming colonies is reduced but the colonies that $\overline{\frac{\bar{N}}{\bar{m}}}$ do form are usually normal, with a normal cluster-to-colony $\frac{\Phi}{\Phi}$ ratio. In the preleukaemic variant there is an alteration in the growth pattern and modification of the cluster-to- $\infty$ colony ratio often several months before any clinical or $\vec{\circ}$ haematological features of leukaemia become apparent. ${ }^{8} 9 \overrightarrow{\vec{\omega}}$

The second type of refractory anaemia, proliferative dysplasia, also occurs in elderly patients and presents with $\frac{5}{3}$ pancytopenia and reticulocytopenia. ${ }^{5}$ The bone marrow is of normal cellularity with no increase in the proportion of $\stackrel{\infty}{+}$ myeloblasts; the unusual features are a marked degree of $\mathcal{N}$ dyserythropoiesis and an increased amount of reticulum, though there is no obvious fibrosis. The first impression is of a myeloproliferative disorder, but ferrokinetic studies show an ${ }_{\circ}^{\infty}$ aplastic pattern, and in the absence of any extramedullary erythropoiesis the most likely explanation is that the disorder is $\omega$ a variant of aplastic anaemia. There is no evidence that it is preleukaemic.

"Primary" refractory anaemia probably results from several $\stackrel{\frac{\infty}{\hookrightarrow}}{\oplus}$ different pathogenetic mechanisms. In a recent study soft agar $\vec{\oplus}$ colony forming unit assays of the bone marrow of a group of. patients with refractory anaemia cocultured with normal marrow showed three distinctive growth patterns. ${ }^{10} 11$ In one, colony formation was low but not suppressed by normal cells, suggesting a defect intrinsic to the stem cell or progenitor. A second group showed normal colony formation, again with $\unrhd$ no evidence of suppressor activity, suggesting that in these $\overrightarrow{\overrightarrow{0}}$ cases the myelopoietic defect was due to an abnormality in the microenvironment. The third group showed low colony formation in the assay and suppression of colony formation by normal marrow, suggesting that this defect may result from suppressor-cell action. Similar mechanisms have been shown in aplastic anaemia; possibly aplastic anaemia and the two 3 forms of refractory anaemia are part of a spectrum of pancytopenia with a common pathogenesis. The extent of overlap between the conditions and of evolution from one to the other 0 remains to be charted.

How the individual patient suffering from a refractory $\sigma$ anaemia should be managed is uncertain, and there has been some debate whether patients with refractory anaemia with excess of myeloblasts should be treated as having acute $N$ leukaemia irrespective of the clinical manifestations or as $\omega$ having aplastic anaemia and be treated with androgens. We have no standard and uniform protocol of treatment, but the $\frac{0}{\Phi}$ laboratory culture studies described might help in deciding $\stackrel{?}{?}$ whether in an individual patient the treatment should be 7 directed primarily towards stem-cell replacement, stimulation $\stackrel{\circ}{\stackrel{\circ}{\mathbb{D}}}$ of haemopoiesis, or immunosuppression.

1 Bomford RR, Rhoads CP. Refractory anaemia. $Q$ f Med 1941 ;10:175-281.

2 Lewis SM, Verwilghen RL, eds. Dyserythropoiesis. London: Academic o Press, 1977.

${ }^{3}$ Dreyfus B, Sultan C, Rochant $\mathrm{H}$, et al. Anomalies of blood group antigens and erythrocyte enzymes in two types of chronic refractory anaemia. Br f Haematol 1969; 16:303-12.

- Duhamel G, Muratore R, Byron P. Anémies réfractaires avec myéloblastose partielle. Analyse d'un protocole, purtant sur 77 cas. IIRésultats de l'examen des biopsies médullaires. Nouv Rev Fr Hematol Blood Cells 1976;16:81-6. 
${ }^{5}$ Gordon-Smith EC. Bone-marrow failure: diagnosis and treatment. $\mathrm{Br} \mathcal{F}$ Haematol 1969;16,suppl: 167-75.

${ }^{6}$ Najean Y, Pecking A, Broquet $M$. Anémies réfractaires avec myéloblastose partielle. Analyse d'un protocole, groupant 79 cas. I-Caractères cliniques et évolution sous androgénothérapie. Nouv Rev Fr Hematol Blood Cells 1976;16:68-80.

${ }^{7}$ Ricci P, Baccarani M, Zaccaria A, Santucci MA, Tura S. Clinical contribution to the knowledge of hemopoietic dysplasias: long term follow-up of 13 patients with refractory anemia. Acta Haematol (Basel) 1978;60: 10-20.

${ }^{8}$ Milner GR, Testa NG, Geary CG, et al. Bone marrow culture studies in refractory cytopenia and 'smouldering leukaemia.' Br $\mathcal{F}$ Haematol 1977; $35: 251-61$.

9 Faille A, Dresch C, Poirier O, Balitrand N, Najean Y. Prognostic value of in vitro bone marrow culture in refractory anaemia with excess of myeloblasts. Scand f Haematol $1978 ; 20: 280-6$.

10 Valera E, Good RA. Studies on the pathogenesis of refractory anaemia. Am F Med 1980;68:381-5.

${ }^{11}$ Kagan WA, Ascensao JL, Fialk MA, Coleman M, Valera EB, Good RA. Studies on the pathogenesis of aplastic anemia. Am f Med 1979;66: 444-9.

\section{Function of the transplanted heart}

How well does the transplanted (and therefore denervated) heart perform? The immediate and practical answer is, well enough, as the activities of patients such as $\mathrm{Mr}$ Keith Castle have shown. But the physiological aspects have been studied in more detail by Schroeder and his colleagues in Stanford, California. ${ }^{1}$

In the surgical technique of orthotopic cardiac transplantation the patient retains the posterior walls of his own atria. The donor heart is sutured to the atria and great vessels and the surgeon does nothing to the valves, ventricles, arterial supply, and much of the atrial muscle, including in most instances the sinoatrial node. An improvement in cardiac output is usual immediately after the operation, though measurements have shown that the stroke volume and cardiac output remain below normal for the first few days. ${ }^{2}$

In the longer term transplanted hearts do not become innervated again. ${ }^{3}$ The lack of yagal tone is shown by the high resting heart rate, usually $90-100 / \mathrm{min}$, with no sinus arrhythmia. Electrocardiographic monitoring confirms that the heart rate is more or less constant. The pulse rate increases slowly, however, with exercise: peak rates, which are about $150 / \mathrm{min}$, do not occur until after five minutes. Slowing of the heart rate is also delayed as compared with normal. These changes parallel and are probably caused by changes in circulating catecholamine concentrations.

Cardiac catheterisation in healthy recipients has shown normal resting pressures in the transplanted hearts, with outputs in the low normal range. ${ }^{3}$ On exercise the left ventricular filling pressure rises, in contrast to normal subjects, whose filling pressures remain low. As the exercise continues and the heart accelerates so the filling pressure falls towards normal again, while the cardiac output progressively rises. Both at rest and on exercise the arteriovenous oxygen difference is wider than normal for a given oxygen uptake. Moreover, during exercise arterial lactate concentrations rise unduly. These differences suggest that the transplanted heart, though capable of increasing its output, does not quite meet the needs of the body, probably because of the limitation of stroke volume.

Left ventricular volumes have been calculated in a few recipients who have had tantalum markers attached to the donor left ventricular muscle at the time of operation and who have been examined later by fluoroscopy. ${ }^{4}$ In these circumstances atrial pacing causes a reduction in ventricular volumes and no change in cardiac output. Increasing the venous return by raising the legs augments left ventricular end-diastolic and stroke volumes and increases the cardiac output without changing the heart rate. These results confirm the transplanted heart's dependence on the Frank-Starling mechanism (which relates the force of contraction to the stretching of the heart muscle), as suggested by the changes in filling pressure on exertion.

The healthy transplanted heart is, therefore, slightly embarrassed by its lack of innervation. The lack of vagal tone is apparent as a resting tachycardia, and the lack of sympathetic drive limits the increase in stroke volume on exertion. Nevertheless, the denervated heart manages to perform adequately for most levels of activity, adjusting its stroke volume by the Frank-Starling mechanism and its rate in response to circulating catecholamines.

${ }^{1}$ Schroeder JS. Hemodynamic performance of the human transplanted heart. Transplant Proc 1979;11:304-8.

2 Stinson EB, Caves PK, Griepp RB, Oyer PE, Rider AK, Shumway NE. Hemodynamic observations in the early period after human heart transplantation. $\mathcal{F}$ Thorac Cardiovasc Surg 1975;69:264-70.

${ }^{3}$ Clark DA, Schroeder JS, Griepp RB, et al. Cardiac transplantation in man. Review of first three years' experience. Am f Med 1973;54:563-76.

4 Ingels NB, Ricci DR, Daughters GT, Alderman EL, Stinson EB. Effects of heart rate augmentation on left ventricular volumes and cardiac output of the transplanted human heart. Circulation 1977;56,suppl 2: 32-7.

5 Pope SE, Ingels NB, Daughters GT, Schroeder JS. In vivo demonstration of the Frank-Starling mechanism in the human denervated heart. $A m \mathcal{F}$ Cardiol $1978 ; 41: 432$.

\section{Mechanisms of chemical carcinogenesis}

Research workers in carcinogenesis are fired by two considerations. Firstly, they hope that better understanding of its mechanisms will lead to the possibility of preventing human cancer. Secondly, their study of the life processes that may be relevant to carcinogenesis by using the latest molecular biological techniques adds to the store of human knowledge and is intellectually satisfying. Unfortunately, those who know most about human cancer and those best able to use new molecular biological techniques constitute different populations with only limited overlap. One consequence of this divide has been the recent fashion for the results of a laboratory experiment, completed in only a few hours, and in the absence of evidence of other kinds, to be interpreted as indicating that man should change his life style in some vital way. How we can best and most quickly check whether man will really benefit from such proposed changes is thus one of the most important questions to be answered.

In his introduction to the British Medical Bulletin's recent review of chemical carcinogenesis, ${ }^{1}$ Peter Brookes indicates that during the past 15 years most progress has been made in our understanding of the tumour-initiating stage of carcinogenesis. What we need to do now, he suggests, is to try to elucidate the nature of tumour promotion in terms of molecular mechanisms. The past 15 years has indeed seen rapid advances in knowledge of how chemically unreactive substances may be converted in vivo to electrophilic metabolites capable of binding to DNA, of the nature of damage to DNA, and of the ways in which such damage may be correctly or incorrectly 